\title{
Efficacy and mode of action of blossom thinners on 'Fuji More' apple trees
}

\author{
Lucas De Ross Marchioretto ${ }^{\mathrm{a}, *}$, Andrea De Rossi ${ }^{\mathrm{b}}$, Leonardo Oliboni do Amaral ${ }^{\mathrm{a}}$, \\ Ana Maria Alves de Souza Ribeiro ${ }^{a}$ \\ ${ }^{a}$ State University of Santa Catarina (UDESC), Center of Agroveterinary Sciences (CAV/UDESC). Avenida Luis de Camões, 2090, Lages/SC, 88520-000, Brazil \\ ${ }^{\mathrm{b}}$ Brazilian Agricultural Research Corporation (EMBRAPA Grape and Wine), Research Station of Temperate Climate Fruticulture (EFCT). Br 116, s/n, Vacaria/RS, 95200- \\ o00, Brazil
}

\section{A R T I C L E I N F O}

\section{Keywords:}

Mechanism of action

Full bloom

Alternative

Thinning

Pollen tube growth

Pollen tube stoppage

\begin{abstract}
A B S T R A C T
The objective of this study was to investigate the mechanism of action of the treatments: Ammonium thiosulfate (ATS), benzyladenine (BA), GA $4+7+\mathrm{BA}$, foliar fertilizer, lime sulphur (LS), LS + mineral oil, mineral oil, NAA, urea, and vegetal oil in the interaction of these treatments with: 1) pollen grain germination, 2) stigma/style pollen tube (PT) development, and 3) the effectiveness of the treatments in field conditions on decreasing crop load and enhancing fruit quality of 'Fuji More' apple trees. In experiment 1 it was evaluated the effect of the treatments in inhibiting the in vitro pollen germination of 'Maxi Gala' apples. In Experiment 2 it was evaluated in vivo 'Maxi Gala' pollen germination in 'Fuji' pistils to assess the effect of the treatments applied $24 \mathrm{~h}$ before and after the pollination, in three portions of the styles. In experiment 3 it was evaluated the effect of the treatments sprayed at $90 \%$ full bloom in a commercial 'Fuji More' apple orchard on the variables: fruit set, crop load, yield efficiency, mean fruit weight, cluster size, fruit height and diameter, total soluble solids, flesh firmne, mean seed number, skin russet and red color. ATS reduced in vitro pollen germination and caused the greatest damage to the stigmas/styles, while in the field, it was effective to reduce crop load. Treatments containing LS were the most effective to reduce in vitro pollen germination, but the in vivo essay, mode of action seemed to be related to arresting pollen tube growth, and in the field these treatments caused severe russeting. Mineral and vegetal oil do not have direct effect on pollen germination, but arrest pollen tube growth, and in field conditions mineral oil and ATS reduced crop load. All growth regulators $\left(\mathrm{BA}, \mathrm{GA}_{4+7}+\mathrm{BA}\right.$, and NAA decreased greatly crop load and increased fruit weight and quality.
\end{abstract}

\section{Introduction}

With the introduction of apple crop in Brazil during the $70^{\prime}$ through governmental incentives there was a wide expansion of the orchards, and along with the research and the improvement of the techniques during the past decades, at the cropping season of 2017/2018, in Brazil it was produced 1.25 million tonnes of the fruit. In the last decades apple fruit consumption has been increasing in Brazil, concomitantly with the expansion of the planted area. These factors are a consistent proof that apple became from an unfamiliar fruit by the Brazilian customers many years ago, to the third most consumed fruit nowadays. In addition, Brazil became from an importer to an exporter of apples to many countries in the EU and Middle East (Brazilian Apple Yearbook, 2018).

The most effective way of improving apple fruit quality, i.e. higher size, skin red color, total soluble solids is through the reduction of the crop load (Link, 2000). Although, to reach better results, the apple fruitlet thinning has to be done near blooming, as from this stage up to ten days later there is an intense cell division in the fruitlet, which is highly influenced by competition among fruitlets and the growing shoots (Lakso and Goffinet, 2013). In addition, these authors state that for an apple tree to produce marketable fruits, it is necessary to drop more than $90 \%$ of the fruitlets. Goffinet et al. (1995) found that thinning affects essentially fruitlet cell division, rather than cell expansion, thus, early thinning leads to more cells in the fruitlet leading to a bigger fruit size at harvest.

Apple fruitlet abscission is strongly related to the canopy's source capacity to supply assimilates to the growing fruitlets; while the fruitlets' sink strength are closely related with the number of leaves existing in the flower cluster; also, the fruitlets' sink capacity is determined by the ability they have to sustain uninterrupted growth without abscising (Iwanami et al., 2012). According to the same authors, in 'Fuji' apples, even fruitlets that decrease the growth rate are not abscised, indicating a strong sink capacity of the fruitlets of this cultivar, considered as hard-

\footnotetext{
* Corresponding author.

E-mail address: lucasdeross@hotmail.com (L.D.R. Marchioretto).
} 
to-thin. In the conditions found in the south of Brazil, Petri et al. (2013) found that 'Fuji Suprema' fruitlets are thinned by benzyladenine only when they have up to $10 \mathrm{~mm}$ of diameter, and sprays at later phenological stages have little effect.

In Brazil, apple fruitlet thinning is done exclusively with growth regulators, but these chemical thinners have inconsistent results for 'Fuji', as weather conditions prior or after the application influence the thinning response, as in most of the years it is needed a complementation with hand thinning, which increases labor input costs and decreases the potential of producing bigger fruits at harvest. The tree response to growth regulators is related to the carbohydrate status of the tree, which a cooler spring with a high incidence of solar radiation makes the tree to produce a surplus of assimilates; in contrast, in a warm and cloudy spring there is a low production, and a high consumption of assimilates leading to a deficit of stored carbohydrates, making the tree more susceptible to the effects of the chemical thinners (Lakso et al., 2006; Robinson et al., 2011). An alternative to improve the effectiveness of chemical thinning programs is the adoption of blossom thinning with caustic or oily compounds as an alternative to be included in a thinning program.

Ammonium thiosulfate, lime sulphur mixed with fish oil, and corn oil are some examples reported as effective to promote apple flower thinning (Wertheim, 2000; Stopar, 2008; Hampson and Bedford, 2011); although, in the scientific literature little is known about the real mechanism of action, as well as the effectiveness of new alternative compounds to promote apple blossom thinning, making it necessary more detailed information about the mechanism of action of the potential thinning compounds to use these treatments in a proper moment (phenological stage), as they act interfering the pollination process.

There are basically four ways that caustic and oily treatments can act. Firstly, these compounds may damage the flower stigma or create a barrier to the interaction pollen-stigma and obstruct the pollen tube (PT) development (usually applied before pollination). Secondly, the compounds may act on halting the germination of the pollen grain on the stigma, acting as a pollenicide. Thirdly, caustic compounds may cause severe damage to the stigmas preventing the adherence of the pollen grain. And fourthly, these compounds have an indirect effect on the thinning effect as they damage the leaves decreasing the photosynthetic rate and the supply of assimilates to the flower/fruitlets (Embree and Foster, 1999; Ju et al., 2001; Finger et al., 2002; McArtney et al., 2006; Yoder et al., 2009;).

Thus, the objective of this study was to investigate the mechanism of action in the interaction of the treatments with pollen grains; the interaction of the treatments with pollen tubes and stigma/styles; and the treatments effect in field conditions, to assess the effectiveness of the compounds in decreasing crop load, and enhancing fruit quality of 'Fuji More' apple trees.

\section{Material and methods}

\subsection{Experiment 1 - effects of potential blossom thinners on the in vitro germination of pollen of 'Maxi Gala' apples}

In Brazil, apple production basically stands in the apple cvs. Gala and Fuji, so in all the experiments, 'Gala' was used as pollen donor and 'Fuji' was the pollinized cultivar (cross pollinated with 'Gala' pollen). The experiment began on October 10th, 2017 when 'Maxi Gala' was at $50 \%$ full bloom. Flowers of 'Maxi Gala' at the pink balloon stage were collected from an experimental orchard located at EMBRAPA Grape and Wine ( $2830^{\prime} 53^{\prime \prime} \mathrm{S}, 5052^{\prime} 54^{\prime \prime} \mathrm{W}$ ), in the municipality of Vacaria-RS, Brazil. The flowers were placed in a paper bag and taken to the laboratory for pollen extraction. The procedure was done with a scissor containing a hole of $1,5 \mathrm{~mm}$ of diameter near the top, used to remove the petals and the sepals out of the flowers and expose the anthers. Then with a lice comb, the anthers were removed and placed into sulfite paper trays with dimension of $10 \times 20 \mathrm{~cm}$. Thereafter, the trays were placed in a dryer, which constituted of a metal chamber with both extremities opened, containing two lamps of $40 \mathrm{~W}$. At the top of the drying chamber there was a digital thermometer to monitor the temperature, which remained around 20 to $25^{\circ} \mathrm{C}$ throughout a period of $24 \mathrm{~h}$. After this period, the pollen was collected and put inside Eppendorf tubes with capacity of one milliliter and capped with a cotton bundle, and all the Eppendorf tubes were stored in a silica desiccator and stored in the freezer at $-18{ }^{\circ} \mathrm{C}$ until the moment of the experiment set up.

The experiment of the in vitro pollen germination was done in January of 2018, and conducted in a complete randomized design. The procedure to determine the effect of the treatments on the inhibition of 'Maxi Gala' pollen germination (pollenicides) was done as it follows: it was prepared a culture medium that consisted of 100 g.L $\mathrm{L}^{-1}$ of sucrose plus $10 \mathrm{~g} . \mathrm{L}^{-1}$ of agar dissolved in distilled water. To prepare the medium, both sucrose and agar were added into an Erlenmeyer flask and mixed well until complete dissolution, then the flask was heated in the microwave oven until pre-boiling. As the culture medium was still hot and liquid, it was poured in the microscope slides to solidify, using a pipette. In all the microscope slides, there were two PVC discs with $14 \mathrm{~mm}$ of diameter and $3 \mathrm{~mm}$ of height, which were filled with the culture medium.

After the culture medium solidified, the treatments described in Table 1 were sprayed on the slides. To do so, it was prepared a solution of $500 \mathrm{ml}$ for each treatment and all of them were sprayed seven times, using a plastic sprayer with capacity of $500 \mathrm{ml}$. Each treatment was sprayed in three microscope slides, containing two discs, and in each disc was considered as a replication, in a total of six replications per treatment. After the treatments were sprayed, the slides were placed on a table to let them dry partially. As the slides were still wet at touch, the pollen stored at the freezer was sprinkled on the slides. The procedure was to shake the Eppendorf tubes filled with 'Maxi Gala' pollen to

Table 1

Treatments, label names, rate of commercial product, and rate od active ingredients used in all the experiments.

\begin{tabular}{|c|c|c|c|}
\hline Treatment $^{\mathrm{a}}$ & Label name & Rate of Commercial Product & Rate of Active Ingredient \\
\hline Control & - & - & - \\
\hline Ammonium thiosulfate & Ammonium thiosulfate Sigma Aldrich ${ }^{\circ}$ & 25 g.L. $\mathrm{L}^{-1}$ & 24.5 g.L $\mathrm{L}^{-1}$ of ATS \\
\hline Benziladenine + Gibberellic acid $_{4+7}$ & Promalin & $2.5 \mathrm{ml} . \mathrm{L}^{-1}$ & 0.047 g.L $\mathrm{L}^{-1}$ of $\mathrm{BA}+0.047$ g.L $\mathrm{L}^{-1}$ of $\mathrm{GA}_{4+7}$ \\
\hline Benziladenine & Maxcel $^{\circ}$ & $3 \mathrm{ml} . \mathrm{L}^{-1}$ & 0.06 g.L $\mathrm{L}^{-1}$ of BA \\
\hline Foliar fertilizer & CT Green ${ }^{\circ}$ & $0.5 \mathrm{ml} . \mathrm{L}^{-1}$ & $0.03114 \mathrm{~g} . \mathrm{L}^{-1}$ of $\mathrm{N}+0.001035$ of $\mathrm{B}$ \\
\hline Lime sulphur & Super $20^{\circ}$ & $30 \mathrm{ml} . \mathrm{L}^{-1}$ & 6 g.L $L^{-1}$ of $S$ \\
\hline Lime sulphur + mineral oil & Super20 $0^{\circ}+$ Assist $^{\circ}$ & $20 \mathrm{ml} \cdot \mathrm{L}^{-1}+20 \mathrm{ml} \cdot \mathrm{L}^{-1}$ & 4 g. $\mathrm{L}^{-1}$ of $\mathrm{S}+15.12 \mathrm{~g} . \mathrm{L}^{-1}$ of oil \\
\hline Mineral oil & Assist ${ }^{\circ}$ & $20 \mathrm{ml} . \mathrm{L}^{-1}$ & $15.12 \mathrm{~g} . \mathrm{L}^{-1}$ of oil \\
\hline Naphthalene acetic acid & ANA tecnico ${ }^{\circ}$ & 0.0105 g.L $L^{-1}$ & 0.009975 g.L $L^{-1}$ \\
\hline Urea & Ureia Ourofertil $^{\circ}$ & 16 g.L $\mathrm{L}^{-1}$ & 7.20 g. $\mathrm{L}^{-1}$ of $\mathrm{N}$ \\
\hline Vegetal oil & Veget'oil $^{\infty}$ & $25 \mathrm{ml} . \mathrm{L}^{-1}$ & $23.25 \mathrm{~g} . \mathrm{L}^{-1}$ of oil \\
\hline
\end{tabular}

a To all the treatments it was added the surfactant adjuvant Breakthru ${ }^{\circledast}$ at $0.15 \%$ volume/volume. 
release it out of the anthers, and then to impregnate an artist brush with the pollen to be sprinkled in the slides discs. Thereafter, the slides were placed into Petri dishes containing a wet paper filter at the bottom, and then covered with the glass cap to be placed inside a BOD chamber at $25^{\circ} \mathrm{C}$ during three hours. To evaluate the effect of the treatments on the inhibition of the pollen germination, the pollen grains were counted using an optical microscope $(10 \times 100)$. It was counted approximately 100 pollen grains in each disc, and the pollen grains were considered as germinated, when the pollen tubes had a length equal or superior the pollen grain diameter.

The data were subjected to the tests of normality (Shapiro-Wilk test) and homogeneity of variances (Bartlett test) and transformed as needed, then the data were subjected to analysis of variance (ANOVA) ( $p \leq 0.05$ ) through the F test. In case of significance, the means were compared through the Student-Newman-Keuls test ( $\mathrm{p} \leq 0.05)$ using the software SAS v.9.0 (SAS Institute, 2002).

\subsection{Experiment 2 - effects of potential blossom thinners sprayed on 'Fuji More' pistils to assess in vivo germination of 'Maxi Gala' pollen}

On October 20th, 2017 twigs of 20 to $30 \mathrm{~cm}$ of length containing two to three flower clusters at the balloon stage were collected from 'Fuji' trees, planted in an experimental orchard located at EMBRAPA Grape and Wine, located in the municipality of Vacaria-RS (28 30' 53" $\mathrm{S}, 5052^{\prime} 54^{\prime \prime} \mathrm{W}$ ). The twigs were collected from various trees as well as from various sections on the trees' canopies and taken to the laboratory to set the experiment. The twigs were placed into plastic cups with $350 \mathrm{ml}$ of capacity. To avoid cavitation, a section of $10 \mathrm{~cm}$ of the base of each twig was removed, and then the part containing the flowers were placed into plastic cups that were filled with tap water (approx. $150 \mathrm{ml}$ ). For the experiment it was chosen only twigs having six to seven cluster leaves to assure the supply of assimilates during the experiment. The flowers were thinned to leave ten flowers per plastic cup and then the flowers were emasculated.

The experiment was conducted in complete randomized design. To evaluate the effect of the treatments on the germination and growth of the pollen tubes, the experiment was arranged as follows: all the 11 treatments (Table 1 ) were sprayed on the flowers with a plastic sprayer with capacity of $500 \mathrm{ml}$. All the treatments were sprayed to drip point in two periods: $24 \mathrm{~h}$ before pollination ( $24 \mathrm{HBP}$ ) and $24 \mathrm{~h}$ after pollination (24 HAP) in two sets of plastic cups containing ten flowers attached to the branches. It was used 'Maxi Gala' pollen donor, originated from experiment 1 and the pollen was delivered to the stigmas with the finger tip impregnated with pollen. Thus it was possible to evaluate if the treatments acted on inhibiting the pollen germination in the stigma (caustic) or if they arrested the pollen tube growth in the style.

In both times (24 HBP and $24 \mathrm{HAP}$ ) the twigs were left on a table in the laboratory throughout $120 \mathrm{~h}$ to give sufficient time for PT growth into the pistils at room temperature of $25^{\circ} \mathrm{C}$, with fluorescent lamps turned on during daytime. Subsequently, the pistils were cut at three millimeters below the base of the carpel (three millimeters of pedicel) and stored into properly identified Eppendorf tubes with capacity of one millimeter filled with fixative solution composed of formaldehyde, acetic acid and ethyl alcohol in the proportion of 1:1:8, respectively. The Eppendorf tubes were placed inside the refrigerator at $4{ }^{\circ} \mathrm{C}$ and remained until the moment of the evaluation.

The evaluation of the pistils occurred on January of 2018.The procedure was to rinse the pistils three times with distilled water to wash down the fixative solution and than the pistils were placed in a solution of $8 \mathrm{~N}$ of caustic soda $(\mathrm{NaOH})$ during $24 \mathrm{~h}$ to soften the tissues. Then the pistils were washed down three times with distilled water and placed in glass beakers containing a solution of $20 \%$ of sodium hypochlorite during $20 \mathrm{~min}$ to clear the tissues and make the pistils translucent. Then the pistils were washed down three times with distilled water and placed into glass beakers with resorcinol blue staining at $1 \%$ $\mathrm{v} / \mathrm{v}$ ( $1 \mathrm{~g}$ of lacmoid staining dissolved in $100 \mathrm{ml}$ of distilled water), during ten minutes. To prepare the slides for microscopic examination, three drops of resorcinol blue staining dissolved with distilled water (1:2) were poured on the slides and the pistils were placed to accommodate straightly, and then the coverslips were squeezed against the microscope slide to smash the pistils and the interior of them to be exposed.

The counting of the PT was done with an optical microscope $(40 \times 100)$ and it was counted the number of germinated pollen grains on the stigma, and the number of pollen tubes in three portions of the style: between the stigma and $1 / 4$ of the style (portion A); between $1 / 4$ and $1 / 2$ of the style (portion B); and between $1 / 2$ and the entrance of the carpel, in the style (portion $\mathrm{C}$ ). The data was converted in percentage through the equation: $\%$ of pollen tubes $=\frac{\text { number of pollen grains at each portion } \times 100}{\text { number of pollen grains on the stigma }}$.

The experiment was set in a factorial arrangement with 11 treatments and two periods (24 HBP and 24HAP) with ten replications (flowers). The data was subjected to Shapiro-Wilk normality test ( $\mathrm{p} \leq 0.05$ ) and data transformation was done when necessary. Then the data were subjected to two-way analysis of variance (Two-way ANOVA) ( $\mathrm{p} \leq 0.05$ ) through the $\mathrm{F}$ test (11 treatments $\mathrm{x} 2$ periods). In case of significance, the treatments means were compared through the StudentNewman-Keuls test $(\mathrm{p} \leq 0.05)$, and both periods were compared through the $t$-test $(\mathrm{p} \leq 0.05)$ using the software SAS v.9.0 (SAS Institute, 2002).

\subsection{Experiment 3 - effects of potential blossom thinners in reducing 'Fuji More' crop load and on improving fruit quality}

The experiment was carried out in a commercial apple orchard localized in the municipality of Vacaria-RS, Brazil $\left(28^{\circ} 31^{\prime} 41.63^{\prime \prime} \mathrm{S}\right.$, $\left.50^{\circ} 50.09^{\prime} 09.93^{\prime \prime} \mathrm{W}\right)$. The orchard was 11 years old, and the 'Fuji More' was the target cultivar of this study. The apple trees were grafted on M. 9 rootstocks, and tree spacing was $4 \mathrm{~m}$ between rows and $0.80 \mathrm{~m}$ between trees. The climate of the region is classified as humid temperate $(\mathrm{Cfb})$ according to the Köppen-Geiger classification, with well-defined seasons. In the year of 2017 during the months of April to June (endodormancy) it was accumulated 155 chill hours $\leq 7.2^{\circ} \mathrm{C}$ or 618.1 chill units according to the modified North Carolina Model (Hawerroth and Nachtigall, 2017). Throughout the cropping season from, September 2017 to March 2018, mean maximum temperature was $25^{\circ} \mathrm{C}$ and minimum temperature was $13{ }^{\circ} \mathrm{C}$, mean relative air humidity was $80 \%$, and the precipitation was $922 \mathrm{~mm}$, in a total of 62 days with precipitation (Embrapa Uva e Vinho, 2018; Inmet, 2018).

The experiment was conducted on a randomized complete block design with three replications (blocks) containing three subsamples (three plants per block) totalizing nine replication trees per treatment. Each plot consisted of five trees, and one plant of each extremity was discarded (edges), remaining three treated plants. The stage of $70 \%$ full bloom occurred on Sept. 24th, 2017, but due to precipitation, the treatments were applied in the next day on Sept. 25th, 2017 when the trees were at $90 \%$ full bloom. The treatments described in Table 1 were sprayed to drip point with a motorized backpack sprayer, with a spray volume of $1000 \mathrm{~L}^{\mathrm{h} \mathrm{ha}^{-1}}$. During the application of the treatments, the temperature was $17^{\circ} \mathrm{C}$, the wind speed was $4.45 \mathrm{~m} / \mathrm{s}$, the air relative humidity was $81 \%$, and the sky was predominantly with no clouds. No precipitation occurred during three consecutive days following the sprays.

The variables of this experiment were: fruit set and cluster size, crop load, yield efficiency, mean fruit weight, fruit red color, fruit length and diameter, skin russet, flesh firmness, total soluble solids and seed number. Fruit set was determined by selecting three representative branches from the top, middle and bottom portions of the canopy, counting and tagging the number of flower clusters of each branch, and when the fruits had around $20 \mathrm{~mm}$ of diameter (after the "December drop") it was estimated the number of fruits that set since each cluster has the potential to produce five fruits. Cluster size was estimated in 


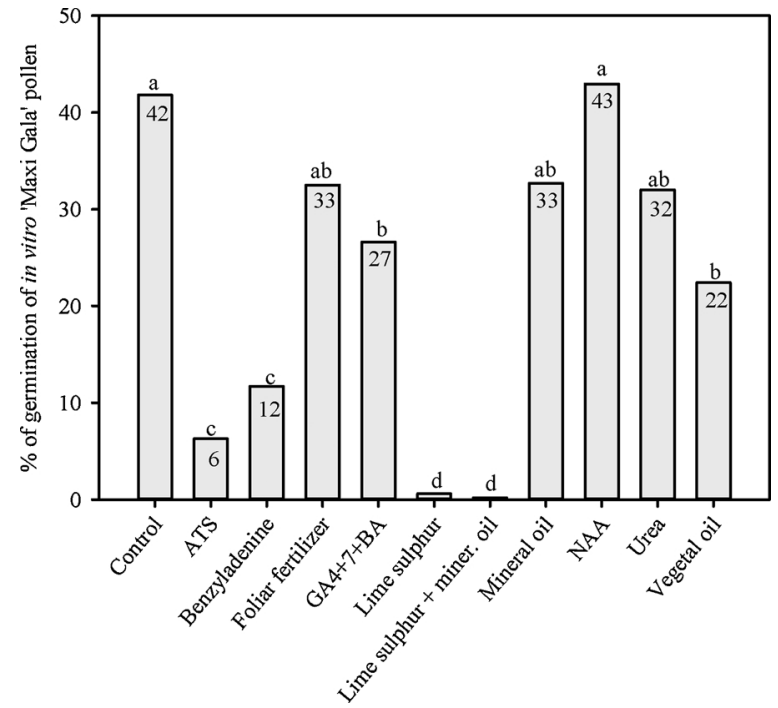

Fig. 1. Percentage of in vitro germination of 'Maxi Gala' pollen grains in function of the effect of the treatments. *Data transformed through the equation $\sqrt{ } \mathrm{y}$. Means followed by the same letter in the bars are not significantly different according to Student-Newman-Keuls test $(\mathrm{p} \leq 0.05)$. Coefficient of variation $=17.8 \%$. (Experiment 1$)$.

December counting the number of clusters with one, two, three, and four or more fruitlets, in the same branches used to determine the fruit set. At harvest, all the fruits of each tree were counted and the yield was weighted, to divide by the trunk's cross sectional area (TCSA), which was measured $13 \mathrm{~cm}$ above the graft union, and then to calculate crop load and yield efficiency, respectively. Furthermore, a sample of 50 fruits per tree was harvested and passed through an industrial grader of the brand Prodol ${ }^{\circledR}$ equipped with an optical color sorter to determine fruit color and mean fruit weight. The grader was calibrated to sort fruits in three classes of red color: $<20 \%, 20-39 \%$, and $40-75 \%$. To estimate mean fruit weight, it was also added to the mean fruit weight data of the harvest by dividing the yield per number of fruits of each tree. Thereafter, a sample of 20 fruits per tree was taken to determine fruit length, diameter, and skin russet, which was grouped in five classes: $0 \%,<10 \%, 10-30 \%, 30-50 \%$, and $>50 \%$. Then the fruits had a portion of the peel removed on both sides of the fruits to determine flesh firmness with a penetrometer equipped a head of $10 \mathrm{~mm}$. Thereafter, the fruits were cut in half to count the number of seeds, and a small portion of the flesh was put in a juicer to determine the total soluble solids with a digital refractometer Atago model PAL-BX/RI.

The data were subjected to the tests of normality (Shapiro-Wilk test) and homogeneity of variances (Bartlett test) and transformed as needed. The variables fruit set, crop load, yield efficiency and mean fruit weight were subjected to analysis of covariance (ANCOVA) using the plant yield as a cofactor to eliminate the effect of yield differences of individual trees on these variables, as the effect of the cofactor was highly significant $(p<0.0001)$ for them. The data of all other variables were subjected to analysis of variance (ANOVA) $(p \leq 0.05)$ through the $\mathrm{F}$ test. In case of significance, the means were compared through the Fisher's protected test LSD ( $\mathrm{p} \leq 0.05$ ). In addition, coefficients of correlation among the variables were calculated. All the statistical procedure was done using the software SAS v.9.0 (SAS Institute, 2002).

\section{Results}

\subsection{Experiment 1 - effects of potential blossom thinners on the in vitro germination of pollen of 'Maxi Gala' apples}

There was significant effect of treatment $(\mathrm{p}<0.0001)$ on negatively affecting the pollen grain germination, as shown in Fig. 1. Both treatments containing lime sulphur (LS) substantially inhibited pollen grain germination, while ATS (ammonium thiosulfate) and, surprisingly, benzyladenine (BA) presented great reduction in the germination. The treatments $\mathrm{GA}_{4+7}+$ benzyladenine and vegetal oil presented intermediate response between the untreated control and ATS or benzyladenine alone. All other treatments, except NAA had little negative effect on pollen grain germination.

\subsection{Experiment 2 - effects of potential blossom thinners sprayed on 'Fuji More' pistils to assess in vivo germination of 'Maxi Gala' pollen}

There was significant interaction between treatments and time of application in the quantity of pollen tubes (PT) present in the portion A (between the stigma and $1 / 4$ of the style) of 'Fuji More' styles ( $\mathrm{p}<0.0001)$ (Table 2). In the interaction of treatments within each time of application, when the treatments were sprayed 24 HBP (hours

Table 2

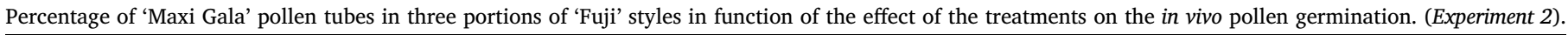

\begin{tabular}{|c|c|c|c|c|c|c|c|}
\hline \multirow[t]{3}{*}{ Treatments } & & \multicolumn{6}{|c|}{ Pollen tubes in each portion of the style $(\%)^{3}$} \\
\hline & & \multicolumn{2}{|c|}{ Portion A } & \multicolumn{2}{|c|}{ Portion B } & \multicolumn{2}{|c|}{ Portion C } \\
\hline & & $24 \mathrm{HBP}^{2}$ & $24 \mathrm{HAP}^{3}$ & 24 HBP & 24 HAP & $24 \mathrm{HBP}$ & 24 HAP \\
\hline Control & - & $79 a b^{n s}$ & $88 \mathrm{ab}$ & $73 a^{\text {ns }}$ & $83 \mathrm{a}$ & $61 \mathrm{a}^{\mathrm{ns}}$ & $76 \mathrm{a}$ \\
\hline ATS & 25 & $45 c^{\mathrm{ns}}$ & $48 \mathrm{c}$ & $32 \mathrm{c}^{\mathrm{ns}}$ & $35 \mathrm{c}$ & $23 \mathrm{c}^{\mathrm{ns}}$ & $26 \mathrm{~cd}$ \\
\hline Benziladenine & 3 & $87 a^{\text {ns }}$ & $87 \mathrm{ab}$ & $66 \mathrm{ab}^{\mathrm{ns}}$ & $67 \mathrm{ab}$ & $55 \mathrm{ab}^{\mathrm{ns}}$ & $59 \mathrm{ab}$ \\
\hline Foliar fertilizer & 0.5 & $78 a b^{\text {ns }}$ & $91 \mathrm{a}$ & $67 a b^{\text {ns }}$ & $81 \mathrm{a}$ & $62 \mathrm{a}^{\mathrm{ns}}$ & $81 \mathrm{a}$ \\
\hline $\mathrm{GA}_{4+7}+\mathrm{BA}$ & 2.5 & $92 \mathrm{a}^{*}$ & $62 \mathrm{abc}$ & $72 \mathrm{a}^{*}$ & $42 \mathrm{bc}$ & $47 \mathrm{abc}^{*}$ & $33 \mathrm{bcd}$ \\
\hline Lime sulphur & 30 & $62 \mathrm{~b}^{\mathrm{ns}}$ & $60 \mathrm{bc}$ & $44 \mathrm{bc}^{\mathrm{ns}}$ & $48 \mathrm{bc}$ & $32 \mathrm{bc}^{\mathrm{ns}}$ & $32 \mathrm{~cd}$ \\
\hline LS + mineral oil & $20+20$ & $86 a b^{\text {ns }}$ & $59 \mathrm{c}$ & $61 \mathrm{ab}^{\mathrm{ns}}$ & $43 \mathrm{bc}$ & $34 a b c^{\text {ns }}$ & $26 \mathrm{~d}$ \\
\hline Mineral oil & 20 & $82 \mathrm{ab}^{*}$ & $65 \mathrm{abc}$ & $53 a b^{\text {ns }}$ & $62 \mathrm{abc}$ & $31 b c^{\mathrm{ns}}$ & $51 \mathrm{abc}$ \\
\hline NAA & 0.0105 & $76 \mathrm{ab}^{\mathrm{ns}}$ & $69 \mathrm{abc}$ & $61 \mathrm{ab}^{\mathrm{ns}}$ & $59 \mathrm{abc}$ & $58 \mathrm{a}^{*}$ & 35 bcd \\
\hline Urea & 16 & $73 a b^{\text {ns }}$ & $88 \mathrm{ab}$ & $49 a b c^{\text {ns }}$ & $70 \mathrm{ab}$ & $39 a b c^{\text {ns }}$ & $50 \mathrm{abc}$ \\
\hline Vegetal oil & 25 & $76 a b^{*}$ & $55 \mathrm{c}$ & $47 \mathrm{abc}^{\mathrm{ns}}$ & $33 \mathrm{c}$ & $40 a b c^{*}$ & $25 \mathrm{~cd}$ \\
\hline$p$ value & - & \multicolumn{2}{|c|}{$<0.0001$} & \multicolumn{2}{|c|}{$<0.0001$} & \multicolumn{2}{|c|}{$<0.0001$} \\
\hline C.V. (\%) & - & \multicolumn{2}{|c|}{10.7} & \multicolumn{2}{|c|}{15.4} & \multicolumn{2}{|c|}{18.4} \\
\hline
\end{tabular}

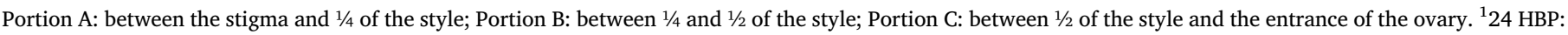

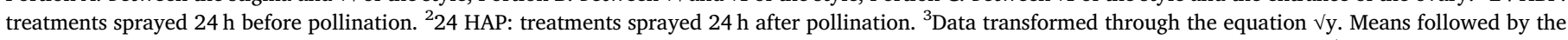

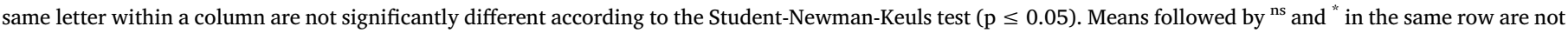

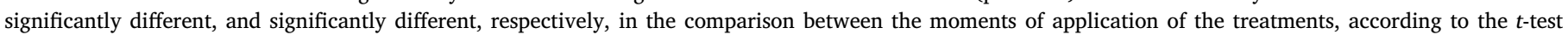
( $\mathrm{p} \leq$ 0.05). C.V. $=$ coefficient of variation. 
Table 3

Fruit set, crop load, yield efficiency and mean fruit weight in function of blossom thinners applied at $90 \%$ full bloom of 'Fuji More' apple trees. (Experiment 3).

\begin{tabular}{|c|c|c|c|c|c|}
\hline Treatments & Rate of commercial product (ml or g.L $\mathrm{L}^{-1}$ ) & Fruit set $(\%)$ & Crop Load (Fruits number. $\mathrm{cm}^{-2}$ TCSA) & Yield efficiency (Kg. $\left.\mathrm{cm}^{-2} \mathrm{TCSA}\right)$ & Mean fruit weight $(g)$ \\
\hline Control & - & 31 a & $13 \mathrm{a}$ & $0.95 \mathrm{a}$ & $74 \mathrm{~b}$ \\
\hline ATS & 25 & $22 \mathrm{bc}$ & $10 \mathrm{~b}$ & $0.90 \mathrm{ab}$ & $78 \mathrm{~b}$ \\
\hline Benziladenine & 3 & $18 \mathrm{c}$ & $6 \mathrm{c}$ & $0.55 \mathrm{e}$ & $94 \mathrm{a}$ \\
\hline Foliar fertilizer & 0.5 & $28 \mathrm{ab}$ & $11 \mathrm{ab}$ & $0.76 \mathrm{c}$ & $75 \mathrm{~b}$ \\
\hline $\mathrm{GA}_{4+7}+\mathrm{BA}$ & 2.5 & $16 \mathrm{c}$ & $7 \mathrm{c}$ & $0.59 \mathrm{e}$ & $94 \mathrm{a}$ \\
\hline Lime sulphur & 30 & 31 a & $11 \mathrm{ab}$ & $0.78 \mathrm{bc}$ & $77 \mathrm{~b}$ \\
\hline LS + mineral oil & $20+20$ & $28 \mathrm{ab}$ & $11 \mathrm{ab}$ & $0.78 \mathrm{bc}$ & $75 \mathrm{~b}$ \\
\hline Mineral oil & 20 & $32 \mathrm{a}$ & $10 \mathrm{~b}$ & $0.75 \mathrm{~cd}$ & $79 \mathrm{~b}$ \\
\hline NAA & 0.0105 & $15 \mathrm{c}$ & $6 \mathrm{c}$ & $0.62 \mathrm{de}$ & $98 \mathrm{a}$ \\
\hline Urea & 16 & 29 a & $11 \mathrm{ab}$ & $0.82 \mathrm{abc}$ & $75 \mathrm{~b}$ \\
\hline Vegetal oil & 25 & 29 a & $11 \mathrm{ab}$ & $0.86 \mathrm{abc}$ & $75 \mathrm{~b}$ \\
\hline p value & - & $<0.0001$ & $<0.0001$ & $<0.0001$ & $<0.0001$ \\
\hline C.V. (\%) & - & 27.1 & 25.05 & 19.48 & 10.7 \\
\hline
\end{tabular}

Means followed by the same letter within a column are not significantly different according to the Fisher's protected LSD test (p $\leq 0.05$ ).

before pollination), the treatments with the lowest quantity of PT was ATS followed by lime sulphur (LS) alone, which had intermediate performance between the untreated control and ATS. When applied 24 HAP (hours after pollination), the treatments with the lowest quantity of PT were ATS, LS mixed with mineral oil, and vegetal oil. In the interaction of periods of application of the treatments within each level of treatment, the treatments $\mathrm{GA}_{4+7}+\mathrm{BA}$, mineral oil, and vegetal oil presented significantly less PT when the treatments were applied 24 HAP.

There was significant interaction between treatments and periods of application in the quantity of PT present in the portion B (between $1 / 4$ and $1 / 2$ of the style) of 'Fuji More' styles ( $p<0.0001$ ) (Table 2). In the interaction of treatments within each time of application, for the treatments sprayed $24 \mathrm{HBP}$ the lowest quantity of pollen tubes was found with ATS, and at some extent, with lime sulphur alone. When applied $24 \mathrm{HAP}$, the treatments with the lowest quantity of PT were ATS and vegetal oil, without any significant difference between them. At some extent, $\mathrm{GA}_{4+7}+\mathrm{BA}$, LS alone, and LS mixed with mineral oil had intermediate performance in decreasing the quantity of PT present in this portion of the style. In the interaction of time of application of the treatments within each level of treatment, $\mathrm{GA}_{4+7}+\mathrm{BA}$ had a lower quantity of PT when the treatment was applied 24 HAP.

There was significant interaction between treatments and time of application in the quantity of PT present in the portion C (between $1 / 2$ and the entrance of the ovary) of 'Fuji More' styles $(p<0.0001)$ (Table 2). In the interaction of treatments in each time of application, when sprayed $24 \mathrm{HBP}$, the lowest quantity of pollen tubes was found with ATS. While, LS alone, and mineral oil had an intermediate reduction in the amount of PT in this portion. When applied 24 HAP, the treatments with the lowest amount of PT were lime sulphur mixed with mineral oil, followed by ATS, lime sulphur alone, and vegetal oil. In the interaction of times of application of the treatments within each level of treatment, $\mathrm{GA}_{4+7}+\mathrm{BA}$, NAA and vegetal oil had significantly lower quantity of PT when the treatments were applied 24 HAP.

\subsection{Experiment 3 - effects of potential blossom thinners in reducing 'Fuji More' crop load and on improving fruit quality}

There was significant treatment effect on the variables fruit set, crop load, yield efficiency, and mean fruit weight ( $p<0.0001)$ (Table 3). The treatments that mostly reduced fruit set were the growth regulators benzyladenine, $\mathrm{GA}_{4+7}+\mathrm{BA}$, and NAA, without any significant difference among them. Whereas, ATS had similar performance of the growth regulators, but with less intensity. All the treatments promoted some level of reduction of the crop load, but it was greatly reduced by all the growth regulators, whereas ATS and mineral oil reduced the crop load with an intermediate response between the growth regulators and the other treatments. All the treatments reduced the yield efficiency at some extent, but it was mostly reduced by benzyladenine and $\mathrm{GA}_{4+7}+$ BA. The treatment NAA presented less reduction of the yield efficiency compared to the other growth regulators, although it was not different from BA or $\mathrm{GA}_{4+7}+\mathrm{BA}$ and mineral oil (intermediate effect). The foliar fertilizer, which has non-ionic surfactant properties also promoted decline in the yield efficiency. Both LS alone or mixed with mineral oil had similar result in reducing yield efficiency at some extent. Only the growth regulators effectively enhanced the fruit weight.

There was significant treatment effect on cluster size on enhancing the quantity of fruitlets produced in one (single) fruitlet clusters ( $\mathrm{p}<0.0003$ ), and four or more fruitlet clusters ( $\mathrm{p}<0.0013)$. In clusters with three fruitlets there was a trend $(\mathrm{p}<0.0958)$ for treatment effect, so it was proceeded to the comparison of the treatments (Fig. 2). Benzyladenine demonstrated to be indeed a selective thinner, as it induced the majority of the fruitlets to be produced in single fruitlet clusters (there was a "singling" effect). $\mathrm{GA}_{4+7}+\mathrm{BA}$ and NAA also increased the amount of fruitlets produced in single fruitlet clusters, but in a lesser extent than BA. ATS did not differ from the untreated control and BA, indicating an intermediate response between these treatments to induce single fruitlet cluster size. In triple and four or more fruitlet cluster size, BA had the lowest amount of fruitlets in this category. Whereas, $\mathrm{GA}_{4+7}+\mathrm{BA}$ also differed from the control, but in a lesser extent than BA. In the cluster size of four or more fruitlets, NAA had intermediate response between the control and BA.

There was significant effect of treatment in the variables fruit height ( $\mathrm{p}<0.0001)$, and fruit diameter $(\mathrm{p}<0.0003)$. Although, for the variables total soluble solids and flesh firmness there was a trend to indicate effect of treatment $(\mathrm{p}<0.0605$, and $\mathrm{p}<0.0660$, respectively), so it was proceeded to the comparison of the means. All growth regulators enhanced fruit height, without any difference among these treatments (Table 4). For fruit diameter, $\mathrm{GA}_{4+7}+\mathrm{BA}$, mineral oil and NAA produced the highest values, while BA had intermediate response between the other growth regulators and the untreated control. The variable total soluble solids (TSS) had the highest value with BA, while the lowest value was found with ATS. Flesh firmness was followed a similar pattern of TSS with the highest value for BA and the lowest with ATS, although none of them differed significantly from the untreated control. Mean seed number was not affected by any treatment.

There was a trend for treatments effect on the classes of russeting $0 \%$ and $<10 \%$ ( $\mathrm{p}<0.0944$, and 0.0870 , respectively), so it was proceeded to the comparison of means, while for the class of russeting 10 to $30 \%$, the effect of treatments was significant ( $<<0.0017)$. The classes 30 to $50 \%$ and $>50 \%$ were not significantly different (Table 5). In the class $0 \%$, the treatments foliar fertilizer, mineral oil, NAA, and urea did not differ from the untreated control, indicating a good amount of fruits without skin russet, while LS and vegetal oil presented the lowest quantity of fruits in this class. In the class $<10 \%$, no treatment differed from the untreated control, but LS mixed with 


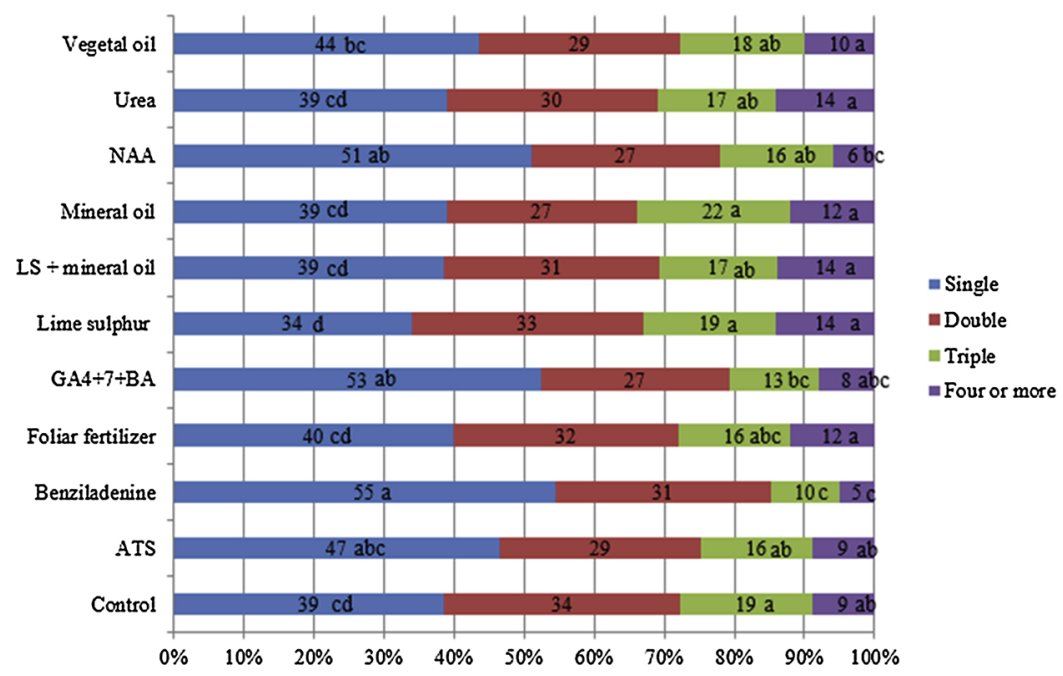

Fig. 2. Fruit cluster size after December drop of 'Fuji More' apple trees in function of the effect of the treatments. "Data transformed through the equation $\sqrt{y}$. Means followed by the same letter within the same cluster size (color) are not significantly different according to the Fisher's protected LSD test ( $\mathrm{p} \leq 0.05$ ). Coefficients of variation: Single $=12.1 \%$; Double $=15.8 \%$; Triple $=29.7 \%$; Four or more $=29.3 \%$. (Experiment 3 ).

Table 4

Fruit height, fruit diameter, total soluble solids, flesh firmness and mean seed number of 'Fuji More' apple fruits in function of the effect of the thinning treatments. (Experiment 3).

\begin{tabular}{|c|c|c|c|c|c|c|}
\hline Treatments & Rate of commercial product (ml or g.L ${ }^{-1}$ ) & Fruit height $(\mathrm{cm})$ & Fruit diameter $(\mathrm{cm})$ & Total soluble solids (Brix) & Flesh firmness $(\mathrm{N})$ & Mean seed number \\
\hline Control & - & $4.91 \mathrm{~b}$ & $6.24 \mathrm{bc}$ & $13.13 \mathrm{ab}$ & $68.29 \mathrm{abc}$ & $6.21 \mathrm{~ns}$ \\
\hline ATS & 25 & $4.85 \mathrm{~b}$ & $6.17 \mathrm{c}$ & $12.20 \mathrm{~b}$ & $66.36 \mathrm{c}$ & 6.37 \\
\hline Benziladenine & 3 & $5.15 \mathrm{a}$ & $6.48 \mathrm{ab}$ & $13.37 \mathrm{a}$ & $70.96 \mathrm{a}$ & 5.93 \\
\hline Foliar fertilizer & 0.5 & $4.86 \mathrm{~b}$ & $6.20 \mathrm{c}$ & $13.16 \mathrm{ab}$ & $69.23 \mathrm{ab}$ & 6.32 \\
\hline $\mathrm{GA}_{4+7}+\mathrm{BA}$ & 2.5 & $5.27 \mathrm{a}$ & $6.58 \mathrm{a}$ & $13.00 \mathrm{ab}$ & $68.60 \mathrm{abc}$ & 5.91 \\
\hline Lime sulphur & 30 & $4.91 \mathrm{~b}$ & $6.18 \mathrm{c}$ & $12.74 \mathrm{ab}$ & $69.03 \mathrm{abc}$ & 6.39 \\
\hline LS + mineral oil & $20+20$ & $4.77 \mathrm{~b}$ & $6.15 \mathrm{c}$ & $13.02 \mathrm{ab}$ & $69.17 \mathrm{ab}$ & 6.02 \\
\hline Mineral oil & 20 & $4.89 \mathrm{~b}$ & $6.54 \mathrm{a}$ & $12.89 \mathrm{ab}$ & $69.42 \mathrm{ab}$ & 6.08 \\
\hline NAA & 0.0105 & $5.26 \mathrm{a}$ & $6.62 \mathrm{a}$ & $13.07 \mathrm{ab}$ & $69.02 \mathrm{ab}$ & 6.11 \\
\hline Urea & 16 & $4.84 \mathrm{~b}$ & $6.20 \mathrm{c}$ & $12.36 \mathrm{ab}$ & $68.26 \mathrm{bc}$ & 6.21 \\
\hline Vegetal oil & 25 & $4.81 \mathrm{~b}$ & $6.12 \mathrm{c}$ & $12.89 \mathrm{ab}$ & $67.87 \mathrm{~b}$ & 6.04 \\
\hline$p$ value & - & $<0.0001$ & 0.0003 & 0.0605 & 0.0660 & 0.4310 \\
\hline C.V. (\%) & - & 3.5 & 4.7 & 9.1 & 4.2 & 9.7 \\
\hline
\end{tabular}

Means followed by the same letter within a column are not significantly different according to the Fisher's protected LSD test ( $\mathrm{p} \leq 0.05$ ).

mineral oil presented the lowest amount of fruits in this class, while the highest level was found for benzyladenine and $\mathrm{GA}_{4+7}+\mathrm{BA}$, mineral oil, and vegetal oil. Although, the class of less than $10 \%$ of russeting can be considered as the characteristic of the cultivar. In the class of skin russet of 10 to $30 \%$ of the fruit, a high incidence was found with ATS, LS alone and mixed with mineral oil, NAA, urea and vegetal oil.

No significant effect of the treatments was found in the variable fruit red color, so the data were not shown.

Table 5

Effect of thinning treatments in 'Fuji More' apple russeting. (Experiment 3).

\begin{tabular}{|c|c|c|c|c|c|c|}
\hline Treatments & Rate of commercial product (ml or g. $\mathrm{L}^{-1}$ ) & \multicolumn{5}{|c|}{ Classes of russeting of 'Fuji More' apple fruits ${ }^{\mathrm{a}}$} \\
\hline Control & - & $50 \mathrm{a}$ & $38 \mathrm{ab}$ & $11 \mathrm{~d}$ & $1 \mathrm{~ns}$ & $0 \mathrm{~ns}$ \\
\hline Benziladenine & 3 & $39 a b c$ & $44 \mathrm{a}$ & $17 \mathrm{~cd}$ & 2 & 0 \\
\hline Foliar fertilizer & 0.5 & $47 \mathrm{a}$ & $33 \mathrm{ab}$ & $17 \mathrm{~cd}$ & 3 & 0 \\
\hline $\mathrm{GA}_{4+7}+\mathrm{BA}$ & 2.5 & $44 \mathrm{ab}$ & $41 \mathrm{a}$ & $15 \mathrm{~cd}$ & 1 & 0 \\
\hline Lime sulphur & 30 & $30 \mathrm{bc}$ & $31 \mathrm{ab}$ & $34 \mathrm{a}$ & 4 & 1 \\
\hline NAA & 0.0105 & $46 \mathrm{a}$ & $34 \mathrm{ab}$ & $21 \mathrm{abc}$ & 1 & 0 \\
\hline Urea & 16 & $46 \mathrm{a}$ & $35 \mathrm{ab}$ & $20 \mathrm{bc}$ & 2 & 0 \\
\hline Vegetal oil & 25 & $28 \mathrm{c}$ & 39 a & $24 \mathrm{abc}$ & 6 & 2 \\
\hline$p$ value & - & 0.0944 & 0.0870 & 0.0017 & - & - \\
\hline C.V. (\%) & - & 21.4 & 19.5 & 32.9 & - & - \\
\hline
\end{tabular}

a Data transformed with the equation $\sqrt{y}$. Means followed by the same letter within a column are not significantly different according to the Fisher's protected LSD test $(\mathrm{p} \leq 0.05)$. 


\section{Discussion}

In this study, with the procedure of counting the pollen tubes in the in vivo essay, it was possible to evidence that ATS was the only treatment with enough causticity to damage the stigmas, as when applied before the pollination it caused the lowest level of germination of pollen since the portion A of the pistil. Although LS alone or mixed with mineral oil presented the highest level of inhibition of pollen germination in the in vitro essay, indicating that when it interacted with the stigmas, it reduced the pollen tube growth at portion $\mathrm{C}$, and it did not interfere greatly the in vivo pollen germination on the stigmas (portion $\mathrm{A}$ ), which is a strong indicator that the floral tissue is capable of adjusting the $\mathrm{pH}$ of the stigma, or the rate used in this experiment was not sufficient to damage the tissue.

As observed in both in vitro and in vivo essays, it was clear that LS and ATS acted on the pollen germination (ATS, LS, and LS + mineral oil) and also damaged the stigma tissue (ATS). In addition, LS reduced the amount of pollen tubes in the portion $\mathrm{C}$ of the style, indicating that it acted in advanced stages of the PT development. The same could be found for mineral and vegetal oil, which had interfered at an advanced development stage of the PT in the in vivo essay, although vegetal oil showed some level in interference in the in vitro pollen germination. It can be indicated that these compounds act only in the pollen grain germination and in the pollen tube development, but does not damage the stigma/style tissue.

A possibility for the pollen tube stoppage in portion $\mathrm{C}$ rather than in portion A of the style, caused by both LS treatments, may be the amount of available $\mathrm{Ca}^{2+}$ needed for pollen tube growth, as the uptake of this ion by the PT is dependent on the $\mathrm{pH}$ of the medium, which may be affected by alkaline compounds like LS and ATS. The PT apex is formed by pectin, which is synthetized in the form of methoxylated esters inside the Golgi dictyosomes, along with the enzyme pectin methyl-esterase, which de-methoxylates the secreted pectin to allow the binding of $\mathrm{Ca}^{2+}$ ions in the acid residues to stabilize the pectin and to strengthen the PT for a consistent growth of the area below the apex (Michard et al., 2017). The $\mathrm{Ca}^{2+}$ enters the pollen tube as the proton pumps actively outflows protons (and lowers the $\mathrm{pH}$ of the exterior) and creates an electrochemical gradient (negatively charged inside the PT apex) to force the inflow of $\mathrm{Ca}^{2+}$ ions (Hepler et al., 2013). It is note worth that the clear zone below the pollen tube apex is rich in mitochondrias and consequently has intense respiration rate, so any compound capable of decreasing the supply of $\mathrm{O}_{2}$ or impede this organelle of working, consequently lead to the arrestment of the PT growth (Hepler et al., 2013; Michard et al., 2017), which may be the case of mineral and vegetal oil.

The PT growth is an event governed by $\mathrm{pH}$ oscillations in the region near the tip (Lovy-Wheeler et al., 2006). The PT apex has acid pH, while the zone below the tip has an alkaline band, and it is where the growth happens; the changes in the proton concentration is dynamic and responsible for PT growth, as in the apex there is an increase in the $\mathrm{pH}$ prior to growth, and thereafter, a $\mathrm{pH}$ decrease in the newly grown section of the PT (Lovy-Wheeler et al., 2006). In the PT apex, it is located the proteins Actin-Depolymerizing Factor (ADF) and Actin-Interacting Protein (AIP), responsible for binding the actin fibres to form the PT body. ADF is activated in high pH (Lovy-Wheeler et al., 2006). While above optimum $\mathrm{pH}$ stimulates ADF to break down the actin, exposing the thorn like ends for binding new actin fibres, and $\mathrm{Ca}^{2+}$ needed, for stabilization of the wall. The acidification slows growth by decreasing $\mathrm{Ca}^{2+}$ uptake and by deactivating the ADF, leading to the destruction of the actin walls by interfering the impairment of the actin cables (Lovy-Wheeler et al., 2006). Holdaway-Clarke et al. (2003) found that in $\mathrm{pH}$ medium of 7 the pollen tubes arrest their growth, and the ideal $\mathrm{pH}$ is around 5.5 .

In the in vitro pollen germination, benzyladenine affected 'Maxi Gala' pollen germination in this experiment. Similar results were reported by Kovaleva et al. (2016) where the authors tested the growth regulators IAA, $\mathrm{ABA}, \mathrm{GA}_{3}$ and kinetin on in vitro germination of Petunia sp. pollen grains and only the cytokinin negatively affected pollen germination. The authors attributed this phenomenon to the non-activation of the proton pumps triggered by the kinetin, thus avoiding the establishment of electrochemical gradients mandatory to the uptake of $\mathrm{Ca}^{2+}$ and other ions used for the PT development.

As the blossom thinners were sprayed in the field in a phenological stage beyond the ideal (sprayed at $90 \%$ full bloom), it is likely that the pollen tubes were too developed to be affected at a point of arresting the development and fecundation, as all the growth regulators, which have little effect on the pollination process, caused the greatest reduction on fruit set, crop load, and yield efficiency. Although, ATS significantly reduced fruit set, and as seen in experiment 2 , even $24 \mathrm{~h}$ after the pollination, the caustic thinner effectively reduced the amount of pollen tubes in all portions of the style, demonstrating the high causticity of the compound. For the variable crop load, both ATS and mineral oil had an intermediate response between the control and the growth regulators, indicating that they may have acted by interfering in the pollination or indirectly by interfering negatively the photosynthesis rate. Similar results were found by Myra et al. (2007), as the authors found that LS had greater effect than ATS in inhibiting in vitro apple pollen germination, while in an in vivo pollen germination essay ATS was slightly more effective than LS, even though both treatments were efficient in reducing apple pollen tube growth. Furthermore, Embree and Foster (1999) on an in vivo pollen germination essay found that ATS at $1.7 \% \mathrm{v} / \mathrm{v}$ was effective to reduce the amount of apple PT at the base of the style, as found in experiment 2; in contrast, the same authors found that urea at 8 or 16 g.L $\mathrm{L}^{-1}$ were also effective, although in our experiment urea $16 \mathrm{~g} . \mathrm{L}^{-1}$ did not interfere expressively pollen germination neither in vitro nor in vivo.

Caustic agents such as LS and ATS cause damage to the leaves and persistent reduction in the photosynthetic apparatus, reducing the supply of assimilates, contributing to the abscission of apple and cherry fruitlets. In addition, vegetal oil and horticultural oils also negatively affect the leaf gas exchange rates, reducing the assimilate production in wine grapes, cherries and apples (Finger et al., 2002; Lenahan and Whiting, 2006; McArtney et al., 2006). The caustic thinners may arrest pollen tube growth in the style when applied 24 HAP for LS mixed with fish oil, but it depends on the environmental temperature, as the higher the temperature the greater the PT growth rate (Yoder et al., 2009). While ATS is effective to prevent pollination when applied until the PT had not reached $50 \%$ of the length of the pistil due to its high causticity and potential to cause damage on the tissues (Maas, 2016).

NAA is commonly used as chemical thinner at petal fall and earlier phenological stages of apple fruitlets, and it is effective at low rates (Wertheim, 2000). The mechanism of action consists on reducing the supply of assimilates to the growing fruitlets by reducing up to $22 \%$ of the stomata conductance, and decreasing the net carbon assimilation rate up to $24 \%$ for 15 days following the leaf absorption of the growth regulator (Stopar et al., 1997). NAA does not affect embryo abortion (Dennis, 2002), and it is corroborated by the results of the experiment 3 , as no difference in seed number was found for the treatments. BA is mostly absorbed by the leaves, and when it is sprayed on the fruits it promotes intense cell division. The response of this growth regulator is highly influenced by the temperature after the application, as in temperatures above $30{ }^{\circ} \mathrm{C}$ the tree's mitochondrial respiration rates are enhanced leading to a quicker depletion of assimilates and then a greater thinning response. Similar to NAA, BA reduces the net photosynthesis between 10 and $15 \%$ in the first 8 days following spray (Yuan and Greene, 2000a). Yuan and Greene (2000b) related that BA promotes embryo abortion and it may lead to fruitlet abscission, but as seen in experiment 3 no effect on seed number was found, thus it is likely that in our experiment BA acted on the carbon partitioning dynamics.

NAA seemed to be the least selective (less capable of "singling" the clusters) thinner compared to $\mathrm{BA}$ and $\mathrm{GA}_{4+7}+\mathrm{BA}$, as it presented cluster sizes of three, and four or more fruitlets equivalent to the 
untreated control, even though the growth regulator increased significantly fruit weight. Black et al. (1995) reported that NAA only increased fruit weight when no other fruitlets were present in the clusters, but the fruitlet located at the king flower position, and when more fruitlets were present in the cluster (other than the one in the king flower position), NAA reduced fruit size in $11 \%$. In the experiment 3 ATS was more effective than LS in inducing single fruitlet clusters; in opposition, Hampson and Bedford (2011) reported opposite effect, as LS mixed with fish oil $2+2 \% \mathrm{v} / \mathrm{v}$ was more effective than ATS at $1.6 \% \mathrm{v} /$ $\mathrm{v}$ in "singling" the clusters of 'Ambrosia' apples. The treatments mineral and vegetal oil had no effect on the cluster size distribution. Vegetal oil is effective in reducing tree crop load, but when applied in early stages of flowering, from pink balloon to not later than $20 \%$ full bloom ( Ju et al., 2001). According to these authors, vegetal oil increased the amount of apple fruitlets produced in single fruitlet clusters. In the experiment 3 , vegetal oil had intermediary performance between the growth regulators and the untreated control, even though it was sprayed at $90 \%$ full bloom, it promoted changes in the cluster size distribution at some extent.

In experiment 3 fruit weight had a high negative correlation with crop load (-0.74), compared to yield efficiency and fruit set $(r=-0.56$ and -0.53 , respectively), it is reinforced that to increase fruit weight, it is necessary to adjust crop load, which is a reason of canopy volume per number of fruits left in the tree. An effective thinning of flowers/fruits is not only related to the amount of fruits that are abscised, but the distribution of the fruitlets in the flower clusters also matters. In the phase from anthesis until 10 days later, there is intense competition for assimilates among growing shoots and expanding leaves, the fruitlets in the tree and the fruits within the same cluster (Lakso and Goffinet, 2013). To produce fruits with bigger size and weight, the fruitlets should be produced mostly in single fruitlet clusters (in the king flower position), as it is better supplied with assimilates, leading to a more intense cell division rate, and so, producing more elongated fruits (Westwood and Blaney, 1963; Jakopic et al., 2015). In the experiment 3, fruit weight was more correlated with fruit height than fruit diameter $(r=0.81$ and 0.55 , respectively). Notwithstanding, all growth regulators made the trees to produce the most elongated fruits with the highest weight.

In hand thinned apple trees, as the crop load is lower the fruits tend to get bigger, but with lower flesh firmness and total soluble solids (TSS) (Salvador et al., 2006). In experiment 3, BA treated trees produced fruits with higher TSS and higher flesh firmness, compared to the other treatments. Moreover, flesh firmness had a high correlation $(r=0.67)$ with TSS, and inverse correlation with yield efficiency $(r=-0.57)$. This is an indicative that with the lower plant yield, more assimilates could be shifted to the fruits. Similar results were reported by Bound and Wilson (2007), where apple fruitlet thinning with BA after ATS at full bloom brought additional effects such as increased fruit size, firmness, and TSS in 'Delicious' apples. BA besides promoting fruit thinning also has additional effect in enhancing cell division, as it is a cytokinin, and was applied in the phase of intense cell division (anthesis) in this experiment. Whereas NAA does not interfere in the cell division speed, but it has an influence in increasing the cell expansion rate, increasing fruit size (Wismer et al., 1995).

Fruit russeting was accentuated by the caustic treatments ATS and LS alone or mixed with mineral oil. Russeting is dependant of rate of these agents, the weather conditions and the apple cultivars (Link, 2000). Bound and Jones (2004) reported that ATS caused russeting in 'Delicious' apples only at rates above 4\% v/v. Stopar (2004) found no russeting promoted by LS sprayed at bloom in similar rate of this experiment. Although, Stopar (2008) found no russeting on LS treated plants, while vegetal oil caused russeting in three apple cultivars.

\section{Conclusion}

These results suggest that ATS interferes on the pollen germination and causes severe damage to the stigma/style tissues, while mineral oil and/or LS interfere negatively on the pollen tube growth, hampering the fecundation of the ovaries. Due to the aggressiveness of ATS, it has more flexibility to be used, at earlier or later flower phenological stages. LS also affects PT growth within the style, but for future studies, the thinner will need to be sprayed once or twice at earlier phenological stages (e.g. 20 and/or 50\% full bloom) to be effective.

When sprayed at $90 \%$ bloom, ATS and mineral oil decrease crop load. Whereas, the growth regulators $\mathrm{BA}, \mathrm{GA}_{4+7}+\mathrm{BA}$ and NAA are strong thinners at this phenological stage, and they improve fruit quality of 'Fuji More'. Although, the response found for these growth regulators is not the targeted for blossom thinning, as the purpose of thinning at this stage is to reduce part of the flowers and serve as a complement to fruitlet thinning. Therefore, the thinning effects seen for both ATS and mineral oil are more appropriate to achieve the objective of blossom thinning of 'Fuji More' apples trees, even though no improvement in fruit quality is induced by these compounds.

\section{Acknoledgements}

The authors acknowledge Coordenação de Aperfeiçoamento de Pessoal de Nível Superior (CAPES) for the scholarship (grant number DS/1635851); Empresa Brasileira de Pesquisa Agropecuária (EMBRAPA) for the infrastructure and the labs; and Randon Agro Silvo Pastoril (RASIP) for the trees in their commercial orchard, used in the field experiment.

\section{References}

Bound, S.A., Jones, K.M., 2004. Ammonium thiosulphate as a blossom thinner of 'Delicious' apple, 'Winter Cole' pear and 'Hunter' apricot. Aust. J. Exp. Agric. 44, 931-937. https://doi.org/10.1071/EA03161.

Bound, S.A., Wilson, S.J., 2007. Ammonium thiosulfate and 6-benzyladenine improve the crop load and fruit quality of 'Delicious' apples. Aust. J. Exp. Agric. 47, 635-644. https://doi.org/10.1071/EA05217.

Brazilian Apple Yearbook, 2018. Brazilian Apple Yearbook. Gazeta Santa Cruz Publishing, pp. 56.

Dennis Jr., F.G., 2002. Mechanism of action of apple thinning chemicals. HortScience 37 (3), 471-474.

Embrapa Uva e Vinho, 2018. Agrometeorologia - Vacaria/RS. Accessed at: Jun. 26, Retrieved from:. https://www.embrapa.br/en/uva-e-vinho/dados-meteorologicos/ vacaria/-/asset publisher/SL3WxNTudP12/content/2016-agrometeorologia-vacariaresumo-anu-1/1355300 ? inheritRedirect $=$ false \&redirect $=$ https $\% 3 \mathrm{~A} \% 2 \mathrm{~F} \% 2 \mathrm{Fwww}$. embrapa.br\%2Fen\%2Fuva-e-vinho\%2Fdados-meteorologicos\%2Fvacaria\%3Fp_p_id \%3D101_INSTANCE_SL3WxNTudP12\%26p_p_lifecycle\%3D0\%26p_p_state \%3Dnormal\%26p_p_mode\%3Dview\%26p_p_col_id\%3Dcolumn-2\%26p_p_col_pos \%3D5\%26p_p_col_count\%3D7.

Embree, C.G., Foster, A., 1999. Effects of coatings and pollenicides on pollen tube growth through the stigma and style of 'McIntosh' apple blossoms. J. Tree Fruit Prod. 2 (2), 19-32. https://doi.org/10.1300/J072v02n02_03.

Finger, S.A., Wolf, T.K., Baudoin, A.B., 2002. Effects of horticultural oils on the photosynthesis, fruit maturity, and crop yield of winegrapes. Am. J. Enol. Vitic. 53 (2), 116-124.

Hampson, C., Bedford, K., 2011. Efficacy of blossom thinning treatments to reduce fruit set and increase fruit size of Ambrosia and Aurora golden Gala ${ }^{\mathrm{TM}}$ apples. Can. J. Plant Sci. 91, 983-990. https://doi.org/10.4141/cjps2011-070.

Hawerroth, F.J., Nachtigall, G.R., 2017. Boletim Agroclimático. Embrapa Uva E Vinho. Accessed at: Jun. 26, 2018 Retrieved from:. http://ainfo.cnptia.embrapa.br/digital/ bitstream/item/168790/1/Boletim-junho-2017-Final.pdf.

Hepler, P.K., Rounds, C.M., Winship, L.J., 2013. Control of cell wall extensibility during pollen tube growth. Mol. Plant 6 (4), 998-1017. https://doi.org/10.1093/mp/sst103.

Holdaway-Clarke, T.L., Weddle, N.M., Kim, S., Robi, A., Parris, C., Kungel, J.G., Hepler, P., 2003. Effect of extracellular calcium, $\mathrm{pH}$ and borate on growth oscillations in Lilium formosanum pollen tubes. J. Exp. Bot. 54 (380), 65-72. https://doi.org/10. 1093/jxb/erg004.

Iwanami, H., Moriya-Tanaka, Y., Honda, C., Wada, M., Moriya, S., Okada, K., Haji, T., Abe, K., 2012. Relations among apple fruit abscission, source strength, and cultivar. Sci. Hortic. 146, 39-44. https://doi.org/10.1016/j.scienta.2012.08.017.

Ju, Z., Duan, Y., Ju, Z., Guo, A., 2001. Corn oil emulsion for early bloom thinning of trees of 'Delicious' apple, 'Feng Huang' peach, and 'Bing' cherry. J. Hortic. Sci. Biotechnol. 76 (3), 327-331. https://doi.org/10.1080/14620316.2001.11511371.

Kovaleva, L., Voronkov, A., Zakharova, E., Minkina, Y., Timofeeva, G., Andreev, I., 2016. Regulation of petunia pollen tube growth by phytohormones: Identification of their potential targets. J. Agric. Sci. Technol. 6, 239-254. https://doi.org/10.17265/21616256/2016.04.004.

Lakso, A.N., Goffinet, M.C., 2013. Apple fruit growth. Hist. Soc. Q. 21 (1), 11-14.

Lakso, A.N., Robinson, T.L., Greene, D.W., 2006. Integration of environment, physiology 
and fruit abscission via carbon balance modeling - implications for understanding growth regulator responses. Acta Hortic. 727, 321-325. https://doi.org/10.17660/ ActaHortic.2006.727.38.

Lenahan, O.M., Whiting, M.D., 2006. Physiological and horticultural effects of sweet cherry chemical blossom thinners. HortScience 41 (7), 1547-1551.

Link, H., 2000. Significance of flower and fruit thinning on fruit quality. Plant Growth Regul. 31, 17-26. https://doi.org/10.1023/A:1006334110068.

Lovy-Wheeler, A., Kunkel, J.G., Allwood, A.G., Hussey, P.J., Hepler, P.K., 2006. Oscillatory increases in alkalinity anticipate growth and may regulate actin dynamics in pollen tubes of lily. Plant Cell 18, 2182-2193. https://doi.org/10.1105/tpc.106. 044867.

Maas, F.M., 2016. Control of fruit set in apple by ATS requires accurate timing of ATS application. Acta Hortic. 1138, 45-51. https://doi.org/10.17660/ActaHortic.2016. 1138.6.

McArtney, S., Palmer, J., Davies, S., Seymour, S., 2006. Effects of lime sulfur and fish oil on pollen tube growth, leaf photosynthesis and fruit set in apple. HortScience 41 (2), 357-360.

Myra, M.T., Embree, C.G., Good-Avila, S.V., Morton, V.K., 2007. Assessment of potential organic pollenicides as apple blossom thinners. Int. J. Fruit Sci. 6 (3), 35-52. https:// doi.org/10.1300/J492v06n03 04.

Salvador, F.R., Fisichella, M., Fontanari, M., 2006. Correlations between fruit size and fruit quality in apple trees with high and standard crop load levels. J. Fruit Ornam.
Plant Res. 14 (2), 113-122.

SAS Institute, 2002. SAS User's guide: statistics. SAS Institute. SAS User's guide: statistics Software Version 9.0. Cary, NC, USA.

Stopar, M., 2008. Vegetable oil emulsions, $\mathrm{NaCl}, \mathrm{CH} 3 \mathrm{COOH}$ and $\mathrm{CaSx}$ as organically acceptable apple blossom thinning compounds. Europ. J. Hort. Sci. 73 (2), 55-61.

Stopar, M., Black, B.L., Bukovac, M.J., 1997. The effect of NAA and BA on carbono dioxide assimilation by shoot leaves of spur-type 'Delicious' and 'Empire' apple trees. J. Amer. Soc. Hort. Sct. 122 (6), 837-840.

Westwood, M.N., Blaney, L.T., 1963. Non-climatic factors affecting the shape of apple fruits. Nature 200 (4908), 802-803. https://doi.org/10.1038/200802a0.

Wismer, P.T., Proctor, J.T.A., Elfving, D.C., 1995. Benzyladenine affects cell division and cell size during apple fruit thinning. J.Amer. Soc.Hort.Sci. 120 (5), 802-807.

Yoder, K., Yuan, R., Combs, L., Byers, R., McFerson, J., Schmidt, T., 2009. Effects of temperature and the combination of liquid lime sulphur and fish oil on pollen germination, pollen tube growth, and fruit set in apples. HortScience 44 (5), 1277-1283.

Yuan, R., Greene, D.W., 2000a. Benzyladenine as a chemical thinner for 'McIntosh' apples. I. Fruit thinning effects and associated relationships with photosynthesis, assimilate translocation, and nonstructural carbohydrates. J. Am. Soc. Hortic. Sci. 125 (2), 169-176.

Yuan, R., Greene, D.W., 2000b. 'McIntosh' apple fruit thinning by benzyladenine in relation to seed number and endogenous cytokinin levels in fruit and leaves. Sci. Hortic. 86, 127-134. https://doi.org/10.1016/S0304-4238(00)00142-4. 